\title{
La misión imposible del Presidente Nixon
}

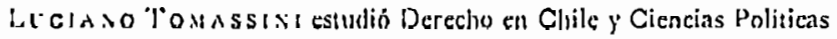
en Estados Unidos. Fue Asistentc del Presidente del Banco Interameriricano de Desarrollo. Actualmentc es Baring Research Fcliow en el Royal Instilutc of Internationa! Aftairs, Londres, y Profesor-investigador del Instituto de Estudios Internacionales de la Universidad de Chile.
\end{abstract}

Si la tarea de un politico consistc en hacer lo que es necesario, la nueva estrategia internacional propuesta por el Presidente Nixon es acertada; pero no lo es tanto si la politiça es el arte de lo posible.

La "moratoria" escalonada que c! pueblo norteamericano ha dirigido a! Presidente Nixon en relación con la guerra del Vietnam ha dado lugar a algunas de las manifestaciones públicas más impresionantes que registra la historia de los Estados Unidos. Los norteamericanos han reiterado de una manera perentoria sus sentimientos contrarios no solamente a esa guerra sino tambićn a la presencia de los Estados Unidos en las tres cuartas partes del mundo. El mandato transmitido al Presidente Nixon consiste en acelerar, en la medida de lo posible, la estrategia de la retirada.

Durante los primeros siete meses de su administración, cl nuevo Prcsidente de los Estados Unidos realizó dos largas traycsias (a Europa, a comienzos del año, y' recientemente al $\Lambda$ sia), $y$ con toda seguri-dad se prepara para efectuar una tercera, que podria llevario al Medio Oriente o incluso a la Unión Soviética. Este nutrido programa de viajes no deberia extrañar a nadic. Nixon sc considera un experto en asuntos internacionales y tiene la convicción - según expresó a Theodore White, autor de The Making of the President, 1968- de que la conducción de las relaciones exteriores constituye la principal tarea de un Presidente nortcamericano. Desde la ćpoca de Woodrow Willson ningún Presidente de los Estados Unidos, con la sola excepción de John F. Kennedy, habia llegado a la Casa Blanca con una percepción más clara de lo que está pasando en el mundo y con un sentido más agudo de la importancia de los acontecimientos internacionales para 
Luciano Tomassini / La misión imposible del Presidente Nixon

el futuro de su pais. Significativamente, desde que el propio Woodrow. Wilson lanzó a los Estados Unidos a la palestra mundial, nunca el pueblo norteamericano ha estado tan consciente de lo que está sucediendo más allá de sus fronteras, ni ha sufrido tantas ansiedades por causa de problemas ajenos. En este sentido - muy elemental- el Presidente Nixon ha captado el estado de ánimo dẹ su país.

Pero su intuición ha llegado más lejos. La flamante sensibilidad del público norteamericano frente a lo que está ocurriendo en otros lugares no significa, ni mucho menos, que se encuentre descoso de asumir responsabilidades en ellos. Siendo los principales autores $y$, por supuesto, usufructuarios de la revolución del televisor y del jet, los norteamericanos se administraron un lavado cerebral colectivo que despertó su interés por otras regiones del mundo y que hizo pasar a la historia su tradicional aislacionismo. Sin cmbargo, es evidente que desde 1941 nunca se habian mostrado menos dispuestos que ahora a poner en juego los recursos que debe utilizar un pais si quiere influir en otros: dinero $y$, sobre todo, soldados. Esta situación no puede escapar al Jefe del Ejecutivo, a quien resulta cada vez más dificil obtener del Congreso el respaldo necesario para cumplir sus compromisos en el extranjero.

Por lo demás, el creciente divorcio entre el poder económico.y militar de que dispone un Estado y su capacidad para influir en el cuadro internacional tampoco escapa al Presidente Nixon. Una de las mayores paradojas de la politica internacional contemporánea es que el desmesurado crecimiento del poderio militar de algunos países les está haciendo cada vez más dificil poner ese poderio al servicio de determinadas politicas, debido a las aterradoras perspectivas que se derivarian de una confrontación nuclear. Como expresó Charles W. Yost en la primera página de la edición de la revista Foreign Affairs de octubre de ig68, "una de las lecciones de los últimos quince años, especialmente conspicua en la guerra de Vietnam, es la de que la capacidad de las grandes potencias, incluso de la más fuerte, para intervenir en otros Estados ha sido erosionada por el tiempo, el espacio y la historia". Los colosos nucleares tienen la capacidad de destruirse unos a otros, pero a menudo no logran ningún resultado cuando tratan de influir sobre paises más débiles. Para verificar esta apreciación basta 


\section{E S T U D I O S I N T E R N A C I O N A L E S}

comparar la efectividad de la política exterior norteamericana hace veinte años y ahora. En los comienzos de la guerra fria los Estados Unidos obtuvieron un conjunto de éxitos impresionantes, como el rescate de Grecia y Turquía de la órbita soviética; la reconstrucción de Europa Occidental, la consolidación de la Alianza Atlántica y los comienzos de la integración europea; la utilización de las Naciones Unidas como un instrumento para reprimir la agresión lanzada por Corea del Norte, y la formulación de los primeros programas de ayuda externa. Poco queda. en pie de ese brillante panorama al finalizar la década de los sesenta. El. fracaso del Gran Designio concebido por el Presidente Kennedy para cimentar una alianza permanente entre los Estados Unidos y una Europa fuerte y unida; la crisis de las Comunidades europeas; la impredictibilidad y la ineficiencia de las actuaciones de las Naciones Unidas; la instalación de un régimen comunista en Cuba; la creciente desconfianza hacia los Estados Unidos por parte de los países situados al Sur del Hemisferio Occidental, y, sobre todo, el trágico punto muerto a que ha llegado la guerra en Vietnam, indican bien a las claras cuán débil es actualmente la relación entre el poderio militar de una potencia mundial y sus resultados efectivos.

¿Para qué arrostrar el descontento de la opinión pública de su pais persistiendo en una politica de intervención global cuyos logros, de todas maneras, han dado pruebas de ser tan limitados?

Las circunstancias señalaban en forma inequivoca a la nueva adimínistración republicana los lineamientos a que deberia atenerse en su actuación internacional. Era conveniente buscar simbolos para describir los cambios que haria falta introducir en la politica exterior estadounidense como consecuencia de esta nueva percepción de la situación mundial. A tal efecto se desenterró, adaptándolo a los nuevos objetivos, el slogan "No más Munichs", en nombre del cual los Estados Unidos se embarcaron en la guerra fria hace más de veinte años. Con el lema "No más Vietnams" los norteamericanos expresan ahora su determinación de desentenderse de las consecuencias de ella. La estrategia de la retirada será extremadamente difícil, $y$ quizás sea imposible del todo. Refirićndose al nuevo lema, el ex Subsecretario de Estado demócrata Georgc Ball observó hace poco que la gente está siempre inventando slogans para despachar aquellos problemas que no admiten una so- 
Luciano Tomassini / La misión imposible del Presidente Nixon

lución fácil. Es cierto que probablemente el Presidente Nixon acometerá una tarea de Sisifo si desea rectificar la orientación globalista que su pais adquirió como herencia de la guerra fria. Pero no sería justo sostener que sus planteamientos se limitan a reflejar "los vientos que corren" o son fruto de la improvisación. Pọr el contrario, se basan en una definición muy precisa de las cambiantes condiciones en que se desenvuelve la política internacional, formulada después de madura reflexión y apoyada en la versión más reciente del pensamiento de destacados académicos norteamericanos. Entre ellos se cuenta, naturalmente, su asesor especial para asuntos de seguridad nacional, profesór Henry A. Kissinger.

Según el profesor Kissinger, la abrumadora superioridad de los Estados Unidos y de la Unión Soviética, que imprimió -un rigido carácter bipolar a las relaciones internacionales durante los últimos veinte años, estaria tocando a su fin. Esto permitirá la emergencia de un nuevo orden mundial, bajo el signo de la multipolaridad². Al terminar la Segunda Guerra Mundial sólo quedaron en pie dos centros de poder en el mundo. La seguridad nacional y las alternativas de acción de todos los demás paises pasaron a depender por completo de sus relaciones con algunas de las grandes potencias. Todo conflicto internacional, por remoto que fuera el teatro de los acontecimientos, debia ser zanjado por una de ellas (actuando probablemente en oposición a la otra) o por medio de un entendimiento entre ambas, pero nunca con prescindencia o en contra de los dos colosos. Hoy dia éstos se ven forzados a re-

$\therefore$ Vor especialmente Henry A. Kissinger, American Foreign Policy, New York, W. W. Norton \& Co., : $9^{6} 9$. Este mismo punto de vista, junto con otras sugerencias brillantes, se encontrará cn Stanlcy Hofman, Gulliver Troubles: or The Setting of American Foreign Policy, New York, McGraw Hill, :g68; en Hans.J. Morgenthau, A New Foreign Policy for the L'niled States, New York, Frederick A. Praeger, 1964. La opinión contraria es esbozada por Zbiguiew Brzezinski en el Department of State Bulletin, 3 de julio de 1967, y elaborada por George Liska en Imperial America: The International Politics of Primacy, The John Hopkins University Press, ig67. 
conocer no sin pesar, como observara Theodore Draper, que esa situación se ha desvanecido:

"Cuando estalló el conflicto cn torno a la captura de! patrullero Pueblo, la primera reacción de Washington fue :ratar de dirimirlo a travís de los rusos, no con los norcoreanos. Los rusos traicionan la misma nostalgia por ventilar sus negocios importantes solamente con los Estados Unidos. En una entrevista concedica al Editor de la revista Life (:8 de lebrero de :968), el Premier Kosyguin se quejaba de que lo único que hacia falta para hacer entrar en vereda a Israel era que los Esiados Unidos llegaran a un acuerdo con la Unión Soviética. "¿Quẻ fuerzas en el mundo podrian resistírsenos?", pregunlaba dolorido el Sr. Kosyguin. Y él mismo se respondia: "Nadie. Pero los Estados Unidos no quieren pactar" Hace veinte o incluso dicz años, ese lamento. podria haber sido tomado en serio. Hoy parece simplemente pintoresco. La Unión Soviética y los Estados Unidos trataron, cada uno a su manera, de prevenir el estallído de la guerra árabe-isracli en junio de 1967 , pero no fueron notoriamente exitosos. Si uno mira a su alrededor en el mundo de hoy, encuentra pocos lugares en los cuales los dos grandes porieres están en condiciones de llegar a un compromiso, y muchos lugares en los cuales ambus no podrian obtener lo que quieren aunque se pusieran de acuerdo ".?

Esta profunda transformación no se debe en primer lugar à la emergencia rebelde de la República Popular China, que según toda evidencia todavia no ha alcanzado la preponderancia mundial de que gozan los dos actuales colosos, aunque bien podria ser que Nixon esté preparando el terreno para "la diplomacia de los tres poderes" que, según el comentarista de The Economișt (2 al 8 de agosto, 1969), será la de los años setenta. Más decisivos han sido dos factores de orden general, a la luz de los cuales la experiencia china aparece por ahora con un carácter episódico. Me refiero al nacionalismo $y$ a lo que Stanley Hoffmann llama la "devaluación de los recursos militares".

Por una parte, los enterradores del nacionalismo, que proliferaron después de la guerra, han descubierto para su sorpresa que, al acercarse la década del setenta, éste goza de buena salud. La historia desautorizó las profecias sugeridas por los títulos de obras que en su época parecieron definitivas, escritas con el propósito de indagar lo que ocurriria "después del nacionalismo", o qué estructuras politicas se formarian

2 Theodore Draper, "World Politics: A NNew Era?", en Encounter, agosto de :968, p. 5. 
"más allá del estado nacional" . La legilimidad adquirida en lodo el mundo por la nación como forma de existencia politica limita la libertad de maniobras de que gozaban las grandes potencias cuando aún imperaba el colonialismo. Hoy la opinión pública mundial rcacciona ante la menor violación de la soberania de un Estado, por muy débil que éste sea y por muy sutil que parezcan las presiones que se tratan de cjercer sobre él. Aunque los cientistas politicos han analizado hasta la saciedad los defectos del nacionalismo $y$ han proclamado su decadencia, esta última no ha sido demosirada $y$, en lo que respecta a esos defectos, son muchos los que comienzan a darse cuenta que el nacionalismo de hoy no es idéntico al del pasado.

Por otra partc ya se ha scñalado la brccha que se cstá abriendo entre el poder militar y la influencia politica. Las grandes potencias han desarrollado ta! capacidad destructiva que se encuentran cada vez más inhibidas para intervenir en conflictos cuya agravación pudiera conducir a un holocausto nuclear. En otras palabras, la imposibilidad de hacer uso de la fuerza militar en su más alto nivel tiene el efecto de reprimir el uso de la coerción en sus niveles más bajos. Una de las consecuencias que se derivan de tal estado de cosas es que las grandes potencias generalmente tienen más éxito cuando procuran negar alguna ventaja al adversario que cuando se proponen conquistar una para ellas mismas, con lo cual la politica internacional de los superpoderes se desarrolla cada vez más en un terreno negativo. Otra de las consecuencias consiste en que tanto las garantias otorgadas por alguno de ellos para la protección de sus aliados como las amenazas dispensadas a aquellos que se atreven a rcbelarse han perdido gran parte de su credibilidad. En el mundo bipolar de hace veinte años el éxito polltico podia scr identificado con el poder militar, pero en los últinos tiempos éste ha perdido parte de su eficacia. El desafio más importante que deberá enfrentar la política exterior norteamericana en los años venideros

${ }^{3} V_{\mathrm{er}}$ E. H. Carr, Vationalism and After, Londres, Wac.Willan, 19ł5, I' Ernst I-laas, Bejond the Vation Stale, Stanford University Press, :964. El resurgimiento del macionalismo ha sido analizado, entre otros, por Rupert Emerson, From Empire to . Vation, Boston, Bucon Press, :g6ri, Dankwart Rustow, \& l'orld of Vattons. Winshington D. C., The Bmokings Institution, 1967 ; Harry G. Johnson, Economic . Fationalism in Old and Neu States, Londres, Alien \& Unwin, :968, y Louis Snyder, The Iev' Matronalism, Ithaca, Corne!l University I'ress, 1968. 
será el de "desarrollar un concepto de orden en un mundo que es bipolar militarmente pero politicamente multipolar"4.

En estos conceptos se fraguó la estrategia que el Presidente Nixon comenzó a poner en práctica a lo largo de sus dos viajes. En ellos se inspira el mensaje que transmitió a los paises asiáticos $y$, en forma un tanto más velada, a los pueblos de ambas Europas.

La nueva estrategia ya habia sido esbozada por el propio Richard Nixon en un articulo publicado por Foreign Affairs en octubre de 1967. Alli Nixon se preguntaba por las perspectivas de Asia "despucs de Victnam". Haciendo gala de una moderación bien caracteristica, el autor no proponia ningún cambio radical. Los Estados Unidos debcrian seguir actuando de conformidad con su condición de primera potencia en el área dicl Pacíico. A tal efecto se recordaba que los Estados Unidos han librado alli tres guerras en el curso de una generación, subrayándose la solidez de los compromisos asumidos. A juicio de Nixon es aili, y no en Europa o en América Latina, donde se originarán los peligros más serios para la paz mundial en el último tercio del siglo $\mathrm{xx}$. Sin embargo, él crec reconocer en esos paises una fuerte tendencin a considerar sus asuntos a la luz de enfoques regionales y a "buscar soluciones asiáticas para los problemas asiáticos" por medio de acciores conjuntas, dentro de un clima de creciente cooperación. Esta tendencia debe ser alentada en forma entusiasta por los Estados Unidos. "Si en el futuro otra nación amiga se vicra enfrentada con una insurrección comunista apoyada desde el exterior - ya sea en Asia, Africa o América Latina - cabe abrigar serias dudas acerca de si la opinión pública $y$ el Congreso norteamericanos darian su respaldo a una nueva intervención unilateral de los Estaỏos Unidos, aunque esta intervención hubicra sido solicitada por el gobierno en cuestión. Esto hace que sea vital para sus propios intereses que las naciones que se encuentran en el camino de las ambiciones de China Comunista se muevan activamente a fin de establecer por cuenta propia un sistema asiático de seguridad colectiva".

4 Henry A. Kissinger, op. cat., p. 79. 
En su viaje a seis paises asiáticos, el Presidente Nixon fue consecuente con lo que habia expresado. Sus objetivos son encontrar un nuevo sistema de seguridad para el Asia que permita a los Estados Unidos reducir sus compromisos militares en esa parte del mundo, sin que ello signifique dejar liberados a su propia suerte a los paises del área. Para lograrlo, los norteamericanos se proponen establecer una nueva división del trabajo entre ellos y sus aliados asiáticos: estos últimos deberán asumir la responsabilidad primordial en el control de nuevos focos de subversión interna (con o sin respaldo externo), manteniendo para ello fuerzas defensivas convencionales apropiadas; los Estados Unidos los ayudarán suministrándoles armas, dinero y entrenamiento. Los ayudarán además en forma directa para garantizar y defender su autodeterminación y su independencia en caso de que sean victimas de una agresión exterior. Las implicaciones prácticas de esta doctrina son que los Estados Unidos mantendrán los compromisos contraidos con sus aliados en virtud de diversos tratados (especialmente en SEATO) y la India continuará disfrutando de la protección no solicitada de su paraguas nuclear. Pero no habrán nuevos tratados ni se ampliarán los existentes. Las tropas americanas no ayudarán a reprimir nuevas insurrecciones, sean o no comunistas. La mejor defensa contra ellas deberá buscarse en el desarrollo económico y social. Al Presidente Nixon le gustaria volver cabezas abajo la "teoria del dominó", responsable de Vietnam (si un pais asiático cede, caerán todos los demás), argumentando que un caso de desarrollo económico exitoso bajo un régimen democrático podria ejercer un importante efecto ejemplificador. Hasta dónde llegará la aplicación de la nueva doctrina y hasta qué punto se aparta de la doctrina anterior, sólo podrá apreciarse si en un caso determinado fracasan los esfuerzos internos, tanto económicos como militares, y surge el peligro de que triunfe una nueva insurrección.

Similar, aunque menos explicito, es el mensaje que ha llevado personalmente al Presidente Nixon en dos oportunidades al viejo continente. Ha sido descartada la idea de que los Estados Unidos deben apoyar a cualquier precio la actual estructura de Europa Occidental, un, concepto que fuera defendido con tenacidad por el ex Subsecretario de Estado Sr. George Ball. Durante su visita a esos paises, en febrero de este año, el Presidente Nixon rompió el bloqueo ideológico que los Es- 


\section{ES TUDIOS I NTERNAGIONALES}

lados Unidos habian impuesto sobre el gobierno de De Gaulle, y se las arregló para reiterar el apoyo de ese país a las instituciones supranacionales existentes -ante todo la otax y el Mercado Común Europeo- abriendo al mismo tiempo la posibilidad de iniciar un diálogo con el General. Los europeos quedaron notificados de que a ellos corresponderá optar entre el acrecentamiento de la unidad europea o la consolidación de esa Europe des Patries que vaticinara De Gaulle. Los nortcamericanos apoyarán la decisión que ellos tomen, cualquiera que sea. Del mismo modo, aunque el viaje de Nixon a Rumania ha'dado lugar a un sinnúmero de conjeturas, resulta claro que, por lo menos, éste quiso demostrar que los Estados Unidos reconocen en el plano doctrinario que la disolución del imperio soviético en Europa Oriental sigue su curso a pesar de Checoslovaquia - sin que ese reconocimiento implique el propósito de interferir en ese proceso-, y que los puentes que la nueva administración desea construir en dirección a la Unión Soviética bien podrian apoyarse previamente en algunos de sus satélites.

Una vuelta al aislacionismo anterior a los años cuarenta pareceria imposible. Pero no hay dudas de que los Estados Unidos, habiéndose dejado llevar demasiado lejos por la marea globalista, están deseando que comience el reflujo.

IV

"La politica exterior norteamericana en este siglo ha tendido a oscilar èntre los extremos de un indiscriminado aislacionismo y de un internacionalismo igualmente indiscriminado"s, reconoció Hans Morgenthau en su último libro. Los principios democráticos se convirtieron en realidad por primera vez en los Estados Unidos. Sintiendo la necesidad de preservar su propia forma política, dicho pais afirmó tempranamente a través de la doctrina Monroe su determinación de hacer del Hemisferio Occidental el lugar de la libertad, $y$ de resistir toda tentativa efectuada por las viejas potencias europeas para trasplantar sus regimenes politicos a esos territorios. No impidió esta doctrina que los norteameri-

5 Hans J. Morgenthau, op. cil., p. 15. 
Luciano Tomassini / La misión imposible del Presidente Nixon

canos abrigaran también desde un comienzo un fuerte sentimiento mesiánico, que Jefferson expresó en carta escrita a John Dickinson (6 de marzo, 1801) al decir: "Un gobierno republicano justo y sólido manțenido aqui constituirá un monumento permanente y un ejemplo propuesto para la imitación de otros pueblos". Al observar el desarrollo de la politica exterior de los Estados Unidos, uno llega a la conclusión de que sus ideales libertarios se han expresado preferentemente en la doctrina del aislacionismo, pero se han ejercido por medio de la intervención.

Como ha observado Robert Osgood, antes de 194! los Estados Unidos demostraron una notable inestabilidad en sus relaciones con el resto del mundo. Esta caracteristica se observa claramente en las grandes fluctuaciones que se produjeron con ocasión de la guerra con España y de la Primera Guerra Mundial, entre una decidida intervención en los asuntos internacionales $y$ un drástico abandono de las posiciones adquiridas. En ambas oportunidades los norteamericanos "asumieron con extraordinario entusiasmo compromisos que ellos mismo repudiaron más tarde"'. Cada uno de estos movimientos nació en medio de un vivo sentimiento de cruzada y se desintegró por obra de una curiosa reacción constituida por una mezcla de arrepentimiento y desilusión. Aparentemente estamos asistiendo a la clausura de un nuevo ciclo, que comenzó con la doctrina Truman y podria terminar con la doctrina Nixon.

Es interesante observar cómo en cada una de las oportunidades anteriores el movimiento de repliegue apareció siempre acompañado de un confuso sentimiento de culpa, expresado en severas criticas a la etapa precedente. El pueblo norteamericano ha buscado una $y$ otra vez en el enclaustramiento una especie de expiación de los excesos cometidos durante sus aventuras de cruzado. En el fondo de su conciencia politica, la famosa sentencia de John Quincey Ádams siempre conservó su validez, o por lo menos la recuperó en el momento oportuno: "Estados Unidos desea la libertad y la independencia de todos, pero sólo es el campeón y el defensor de la suya propia".

Las actitudes aislacionistas se volvieron particularmente agudas en el periodo que medió entre las dos guerras mundiales. En la vispera misma de la segunda conflagración, Charles Beard, el más conspicuo de los

${ }^{6}$ Robert E. Osgood, Ideals and Self-Interest in America's Foreign Relations, The University of Chicago Press, 1953, p. 19. 
EST U DIOS INTER N A C I O N A L E S

analistas politicos norteamericanos, prevenia a su pais contra la tentación de "dictar cátedra a otras naciones", y se oponia que se hiciera uso "del poder de los Estados Unidos para imponer un esquema económico o politico a otros paises". (America in Midpassage, New York, 1939, pág. 455). Ya en The Idea of National Interest Charles Beard habia abogado por una politica que hiciera posible que la economia norteamericaná se desarrollara orientándose hacia el abastecimiento del mercado interno, sin depender excesivamente de las transacciones con el exterior, cuyo aporte era minimizado por aquella época. Al mismo tiempo, el Senador Taft y el ex Presidente Hoover sostenian que la seguridad de los Estados Unidos no dependia de la suerte de ninguna otra nación. Los dos océanos constituian una barrera infranqueable. Norteamérica no podia ser derrotada. De este modo, las concepciones económicas y militares en boga confluian, reforzando los sentimientos aislacionistas sobre los cuales se construia la imagen de una inexpugnable y solitaria Fortress America.

Desde entonces, los Estados Unidos se han embarcado por el camino de un globalismo sin precedentes en la historia, interviniendo activamente en los más remotos rincones del mundo como si su seguridad dependiera de las menores alteraciones que puedan ocurrir en ellos. A partir de la doctrina Truman, los Estados Unidos pusieron en operación el Plan Marshall y la oTaN, y unieron su suerte a la de Europa a través de la Alianza Atlántica, en un formidable esfuerzo para detener a la Unión Soviética; bajo los auspicios de John Foster Dulies suscribieron los tratados que establecieron el CENTO y el CEATO, con los que pretendian tender un "cordón sanitario" en torno a China a lo largo de la gigantesca extensión que separa a Irán de Filipinas; concertaron alianzas equivalentes con Australia y Nueva Zelandia asi como, en menor medida, con Japón y Corea; la Resolución del Golfo de Tonkín les otorgó un cheque en blanco para intervenir en el oriente asiático; asumieron la onerosa obligación de defender al Sud Vietnam e Israel (que están cumpliendo penosamente), y el compromiso no escrito de proteger a la India con su poderio nuclear; todo ello sin contar con que la seguridad del Hemisferio Occidental en su conjunto descansa sobre sus hombros de acuerdo con el Tratado de Rio de Janeiro, que precedió a todos los demás y, según algunos juristas, tuvo el privilegio de servirles de modelo. Para hacer operativos todos esos compromisos los Estados Unidos han tenido 
que inventar una. verdadera parafernalia de instrumentos de intervenciôn, tales como el mantenimiento de flotas provistas de armamentos nucléares $y$ de bases aéreas alrededor de todo el mundo, la cia y los Green Berets, la ayuda externa y la asistencia técnica, sin contar con el envio de fuerzas expedicionarias de vez en cuando y su interminable lucha en las junglas de Vietnam. De esta manera los Estados Unidos se han visto obligados a mantener cerca de un millón de soldados y agentes de seguridad en unos $3^{0}$ paises; está participando en 5 alianzas militarcs regionales; se ha vinculado por medio de tratados defensivos con más de 40 paises, y está suministrando ayuda económica y militar a cerca de 100 naciones.

Todo el mundo sabe cómo los Estados Unidos llegaron hasta esa situación, pero no hay unanimidad cuando uno pregunta por qué se vieron envucltos en clla. Las posibilidades de que cl Presidente Nixon tenga éxito en sus esfuerzos por disociar a los Estados Unidos de la politica globalista con la que se ha identilicado en los últimos veinte años dependen de cuáles sean los verdaderos motivos que lo movieron a lanzarse en ella. ¿Hasia qué punlo los fundamentos de esa politica de intervención global obedecen a un accidente histórico o hasta qué punto están enraizados en el sistema económico $y^{\prime}$ social $y^{\prime}$, por lo tanto, en los intereses $y$ necesidades del pueblo norleamericano?

Si uno realmente quiere avanzar en la búsqueda de tales motivaciones, haria bien en descartar desde la partida la versión de aquellos que, incluso con la mejor intención, destacan los siniestros designios del imperialismo norteamericano, siempre dispuesto a ascgurar por la fucrza el suministro de materias primas y el control de los mercados mundiales. En su formulación clásica, donde generalmente ha permanecido confinada en forma inexplicable, la tesis del grosero imperialismo no correspondc a la complcjidad del sistema industrial contemporáneo ni al cuadro actual de las relaciones internacionales. Es saludable reconocer que esa tesiš ha sido superada, aunque ciertos representantes de ios "intereses imperialistas" continúen con todo candor suministrando prucbas de su vigencia, como aquel Vicepresidente del Chase Manhattan 
Bank que parecia creer que la guerra de Vietnam se estaba librando exclusivamente para beneficio de sus clientes:

"En el pasaclo, los inversionistas extranjeros se han mostrado un tanto cautelosos con resplecto a las perspectivas generales en el surleste nsiático. Debo declarar, sin embargo, que la acción de los Estados Unidos en Victman este año-la cual ha demostrído que los Estados Unidos continuarán brindando protección efectiva a los pueblos libres de la región- ha reconfortado considerablemente tanto a los inversionistas asiáticos como occidentales. De hecho, tengo algunas razones para creer que en hs economias libres del tsia porlria producirse el mismo tipo de crecimiento cconónico que luvo lugar el Europa después que la doctrina Truman ; la orax suministraron un escudo protector. Lo mismo ocurrió en Japón después que la intervención de los Estados Unidos cn Corea removió las dudas de lus inversores"?

Resulta más interesante examinar las explicaciones proporcionadas por los criticos liberales de la politica exterior norteamericana. Síendo en su mayoria norteamericanos, su común denominador radica en que, junto con condenar esa politica, todos ellos absuelven a los Estados Unidos de cualquier responsabilidad por sus actividades intervencionistas.

Generacioncs enteras de ingleses han aligerado su conciencia releyendo la famosa frase de Maculay, scgún el cua! Inglaterra conquisró la mitad del mundo "en un momento de distracción". Buena parte de los criticos libcrales del globalismo norteamericano han adoptado esta explicacón, y para ello han acuñado el concepto de "la politica de la inadvertencia". Nadic planeó el imperio norteamericano; ni siquiera nadie lo quiso. Una y otra vez los Estados Unidos fucron empujados a intervenir en otros lugares por los vicjos cstadistas curopeos, desde Clemenceau hasta Stalin, deseosos de mezclarlo en sus connlictos de poder para inclinar la balanza en determinado sentido, o de sacar las castañas del fuego con la mano del gato. Esta situación se hizo crónica después del colapso de las antiguas potencias a! finalizar la Segunda Guerra Mundial. Sin que nadie supiera cómo, su lugar pasó a ser ocupado por los Estados Unidos. Ronald Steel, uno de los criticos más implacables de la politica intervencionista de este pais, pudo decir que su imperio "llegó a la existencia por accidente $y$ posteriormente fue mantenido por un sentimiento de

7 Conceptos expresidos por Alred Wentworth en julio de $: 965$, citados por Harr; Magdolf en . Monthly Review, noviembre de 8 g66.

- Ver Arthur Schiesinger Jr., The Biller Herilage, Londres, André Deutsch, ig67. 
benevolencia". Asi, de la noche a la mañana, se creó el "imperio accidental" más poderoso que registra la historia.

Una versión más realista de la explicación anterior señala la creación de un vacío de poder en el periodo de postguerra y' recuerda cómo entonces surgió la necesidad de llenarlo, estableciendo alguna fuerza de "policia internacional" para la mantención de la paz. Esa tesis se basa en el argumento de que en la comunidad internacional debe haber una última instancia capaz de dirimir diferendos y de imponer soluciones cuando las partes no son capaces de resolyerlos por si mismas, ya que sin ellá la paz mundial se veria expuesta a graves $y$ continuas amenazas. Las viejas potencias europeas habian cumplido esa función de alguna manera. Lo anterior habia sido especialmente cierto en el del Imperio Británico, hasta el punto de que en aquellos dias su desintegración fue calificada como "el mayor golpe después de la caida de Constantinopla"10. Es cierto que juridicamente esa responsabilidad fue transferida a las Naciones Unidas, pero su ulterior debilitamiento obligó a los Estados Unidos a actuar en forma unilateral, cada vez con mayor frecuencia, en su reemplazo. Aceptando estas premisas, el Presidente Kennedy describió a los Estados Unidos como "un vigilante en las murallas del mundo libre", a lo cual más tarde el Presidente Johnson agregó: "nosotros no escogimos ser los guardianes a las puertas de la libertad" ".

Pero la mayoría de los norteamericannos gusta de pensar que ha sido su proverbial idealismo lo que los ha impulsado a intervenir en los asuntos mundiales. Ellos siempre han estado convencidos de que su forma de vida encierra valores universales y que, con sólo adoptarla como modelo, los pueblos menos afortunados podrian alcanzar la felicidad. La única diferencia entre el pasado y nuestro propio tiempo consiste en que solamente en los últimos veinte años Norteamérica ha estado en posesión de los medios necesarios para revestir de carne sus ideales y asegurar su observancia alrededor del mundo. "La historia y nuestros propios logros nos han conferido la responsabilidad principal en todo cuanto

9 Ronald Stcel, Pax dmericana, New York, The Viking Press, :95\%, p. :5.

${ }^{10}$ Citado en Joscph M. Jones, The Fifteen IVeeks, New York, 1954, p. 80.

${ }^{1 C}$ Citados por Richard $\downarrow$. Barnel, Intervention and Revoluthon: The L'nuted State's in the Third World, New Y'ork, The World Publishing Co., 1968, p. :1. 
EST T D IOS I N TER NA C I ON A L E S

concierne a la protección de la libertad sobre la tierra", dijo el Presidente Johnson en $1965 ; y$, desarrollando este pensamiento, algunos meses más tarde observó: "éste es un sueño muy viejo, pero nosotros tenemos ahora el poder y la oportunidad de convertir ese sueño en realidad" Quizás los Estados Unidos no siempre hayan intervenido con suficiente discernimiento; tal vez una que otra vez cometieran algún error, y hassta es posible que hayan incurrido en cierta "arrogancia del poder" en alguna oportunidad. Pero su política globalista de los últimos veinte años se nutre fundamentalmente de la tremenda energia que brota del sentimiento moralizador del pueblo norteamericano. George Ball ve en ese papel algo único en la historia del mundo, "el ejercicio de una responsabilidad global divorciada de estrechos intereses nacionales o territoriales ${ }^{13}$, y Ronald Steel, nuevamente, expresa esta misma idea. "A diferencia de Roma, nosotros no hemos explotado nuestro imperio. Por el contrario, nuestro imperio nos ha explotado a nosotros, produciendo un tremendo drenaje de nuestros recursos y energías. Por lo demás, a diferencia de la mayoria de los imperios del pasado, el nuestro no fue adquirido en busca de eficiencia o provecho. Fue adquirido porque creimos que teníamos la responsabilidad de defender a todas las naciones del mundo contra el comunismo:114.

Por fin tenemos una pista para descubrir los fundamentos del globalismo. norteamericano. Las explicaciones anteriores, naturalmente, deben aceptarse con beneficio de inventario. Para encontrar la rẹspuesta que buscamos, parece más seguro interrogar directamente a los hechos. Cualquiera que sea el lugar adonde los Estados Unidos han llegado en los últimos veinte años, lo han hecho siempre luchando contra' el comunismo, o so pretexto de hacerlo. Su politica intervencionista se originó en la decisión de embarcarse en esa nueva contienda mundial que fue (o es) la guerra fría. ¿Cómo se entabló esta contienda? ¿Qué características y consecuencias tuvo? ¿De qué modo estaban alli en juego los intereses vitales de los Estados Unidos?

${ }^{12}$ Tomado de The New York Times, 13 de febrero de 1965, y del discurso pronunciado por Lyndon B. Johnson en John Hopkins University, el 7 de abril del mismo año.

${ }^{13}$ Citado por Richard Barnet, op. cit., p. 13.

${ }^{14}$ Ronald Steel, op. cit., p. $7 \%$ 
La guerra fria estalló en Europa y el objetivo inmediato que tuvieron en vista los Estados Unidos al declararla fue detener la expansión soviética en ese continente, pero pronto se extendió al resto del mundo y se convirtió en un conflicto ideológico de magnitudes absolutas. El casus belli lo proporcionó la amenaza de que Grecia y Turquia cayeran dentro del campo comunista, $y$ las primeras escaramuzas tuvieron lugar con motivo de la operación de rescate que se lievó a cabo para evitarlo. Sin embargo, desde un comienzo la doctrina Truman empleó un tenguaje que iba mucho más allá del desafio planteado por esos dos paises. Una operación diseñada para asegurar el equilibrio de fuerzas entre los Estados Unidos y la Unión Sovictica en Europa central, fue presentada como un compromiso para la defensa de las instituciones libres en todo el mundo contra cualquier agresión directa o indirecta. Lo que pudo haber constituido un conflicto de poderes fue definido enfáticamente en términos ideológicos.

La Segunda Gucrra Mundial enseñó al Presidente Roosevelt, primero, y luego al Presidente Truman que los Estados Unidos, cuy'a intervención en el conflicto habia inclinado la balanza en favor de los aliados, tendría que asumir el papel principal en el mundo de postgucrra para la conservación de la paz. También les había enseñado que la conservación de la paz no seria posible si los paises democráticos no adoptaban una "línea dura" frente a las potencias agresoras, y que no cabia alentar muchas esperanzas de que se adoptara dicha línea si la decisión quedaba entregada a sus respectivos pariamentos y a los vaivenes de la politica local. Para garantizar la estabilidad. de los compromisos que iba a asumir los Estados Unidos, la doctrina Truman fue formulada en térmi-. nos deliberadamente categóricos. Ulțeriormente, el alcance contcnido en la letra de la declaración fue ampliado todavia más al cometerse tres errores. En primer lugar, los norteamericanos confundicron sistemáticamente todo caso de subversión comunista con un acto. de imperialismo soviético, presumiendo que las actividades marxislas del mundo entcro estaban controladas por los rusos. En segundo lugar, operaron en la creencia de que el triunfo del comunismo en un pais determinado constituye un fenómeno irreversible que conduce a la instauración de regimenes no susceptibles de evolución y equivale, por consiguiente, a 
ESTUDIOS INTERNACIONALES

la detención de la historia. Por úitimo, enjuiciaron el desarrollo de los asuntos internacionales con un criterio monolítico y aplicaron el calificativo de comunista a todo movimiento que, de algún modo, pretendiera alterar fundamentalmente el slatu quo.

La realidad ha demostrado que estos tres conceptos son erróneos o perjudiciales. Dean Rusk habia declarado en 1951: "Nosotros no reconocemos en las autoridades de Peiping lo que ellas pretenden representar. El régimen de Peiping será un gobierno colonial ruso... pero no es el gobierno de China"'s. El cisma de ese pais tomó por sorpresa a los nortcamericanos, pero éstos no aprendicron la lección. En la presente década les ha resultado tan dificil concebir que en Oriente pueda haber movimientos comunistas que no sean instrumentos de la politica china, como les fue en la década anterior creer que pudieran haber comunistas que no estuvieran sometidos al control de Moscú. Lo mismo cabe señalar con respecto a! carácter irreversible de las revoluciones marxistas. Yugoslavia rompió con el bloque soviético y entabló relaciones muy estrechas con los Estados Unidos (lo cual tampoco fue irreversible, ya que algunos años más tarde fue admitida nuevamente entre los amigos de la Unión Soviëtica), y su caso no es el único. La tendencia norteamcricana a calificar de comunista a todo régimen politico que impulse reformas sociales mediante procedimientos un tanto rudos, interfiera en la libertad de empresa o nacionalice las principales actividades económicas del pais. (especialmente cuando éstas se encuentran en manos norteamericanas), no ha sicio más acertada.

Es justo reconocer que la convicción con que Norteamérica se lanzó en la gucrra fria fue reforzada por las actitudes de la Unión Soviética. Hasta ese momento el comunismo había permanecido confinado dentro de su pais de origen. Las dos principales profecias de Trotsky no sc habian cumplido: la revolución no habia podido extenderse más allá de las fronteras de Rusia y, en cambio, habia demostrado ser perfectamente capaz de sobrevivir sin romper el "encercamiento" de que la habian hecho objeto los paises capitalistas. El lema de la "revolución nundial" conservaba un valor simbólico, pero en la práctica nada tenia que ver con los propósitos de Stalin: hacer que "el socialismo en un país" se convirticra en realidad por cualquier medio. Después de la guerra, ia revolu-

${ }^{25}$ Citado por llans .Morgenthau, ops:cit., p. $3^{2}$. 
ción marxista tuvo por primera vez la posibilidad de expandirse. Por aquella época, los intereses del nuevo Estado ruso ya habian adquirido demasiado peso, por lo cual resultó inevitable que Stalin se esforzara por poner el comunismo internacional al servicio de la política soviética. Al hacerlo se limitaba a poner en práctica lo que habia escrito hacía veinte años: "Un revolucionario es aquel que está dispuesto a defender a la Unión Soviética sin calificaciones y sin reservas, abierta y honestamente...; porque la Unión Soviética es la base del movimiento revolucionario mundial, $y$ este movimiento no puede ser promovido si no es defendida la Unión Soviética" ${ }^{16}$. En la actualidad China ha echado por tierras las esperanzas que alentaban los rusos de ser considerados los lideres de la revolución proletaria mundial. Sin embargo, hay que declarar que los rusos no obtuvieron ese reconocimiento ni siquiera en sus mejores tiempos, por lo menos en forma espontánea. Milovan Djilas recuerda a Stalin formulando esta terrible reflexión: "Quienquiera que ocupa un territorrio, impone también su propio sistema social. Cada uno impone su sistema hasta donde los ejércitos pueden alcanzar. No puede ser de otra manera". (Conversations with Stalin). Puede ser que la memoria de Djilas no seá del todo exacta, pero es interesante comprobar que ninguno de los paises en que la revolución comunista se efectuó en forma espontánea, y no después de su ocupación por el Ejęrcito Rojo, permaneció en la órbita soviética, como lo demuestran los casos de Yugoslavia, China y Albania. Solamente los norteamericanos creyeron a pie juntillas en la validez de las pretensiones soviéticas.

\section{VII}

Una de las más fascinantes maneras de ocupar el tiempo en nuestros dias es discutiendo si la guerra fria ha terminado o no. Por supuesto, la conclusión a qưe se llegue dependerá de la manera en que dicho conflicto haya sido definido. Si el conflicto es definido en términos de una confrontación entre dos poderes - Rusia y los Estádos Unidos - todo indica que pasó a la historia o que, por lo menos, se ha transformado hasta el punto de quedar irreconocible. Pero si es definido en términos de una confrontación ideológica entre democracia y comunismo (o, para tales efectos,

${ }^{26}$ Joscph Stalin, Vorks (.Noscú, 1927), Vol, X, p. 53. 
ESTUDIOS INTERNACIONALES

economias capitalistas y economias socialistas, paises industrializados $y$ paises en desarrollo, o simplemente revolucionarios $y$ defensores del statu quo), la respuesta resulta más compleja. En un libro muy importante - The Cold War as History- Louis Halle argumenta vigorosamente por la primera de estas tesis. Para él, la guerra fria aparece como un capítulo en la confrontación secular entre Rusia y el Occidente, un "espasmo" generado por el colapso de las estructuras de poder dentro de este último campo:

"En el lado occidental, los probiemas de fines de los años cuarenta se han atenuado o han desaparecido. El vigor de Europa occidental ha sido restaurado, y ya no hay ningin temor de que el Ejército Rojo pueda marchar hasta el Cañal de la Mancha. Un statu quo geográfico que parecia demasiado anormal para ser duradero, ha durado por lo menos lo suficiente como para comenzar a parecer normal... Las consideraciones ideológicas están perdiendo importancia, hasta el punto de que el significado del "comunismo" como etiqueta aplicada a paises como Yugoslavia o Polonia ha liegado a ser cada vez más dudoso. A través de lo que se suponia ser una linea de confrontación entre dos campos hostiles, las comunicaciones, los viajes y el comercio están aumentando. Tal como ocurrió en siglos anteriores con el conflicto entre la Cristiandad y el lslam, poderosas fuerzas de cambio han estado transformando las condiciones en que se habia basado la guerra fria"17.

La evidencia indica, en cambio, que la guerra fria es substancialmente una contienda ideológica entre los Estados Unidos y: las fuerzas de la subversión en cualquier parte del mundo. Podrá haberse mitigado el duelo singular entre los Estados Unidos y Rusia, pero la guerra prosigue en otros frentes. Podemos convertir el debate en una cuestión semántica, reservar el concepto de "guerra fria" para la confrontación entre esas dos potencias $y$ buscar otros nombre para los conflictos restantes. Pero queda en pie el hecho de que hay una profunda consistencia entre todos ellos, y una perfecta continuidad entre las diversas fases del proceso. El carácter ideológico de este conflicto fue subrayado deliberadamente por los hombres que elaboraron la doctrina Truman, $y$ ha sido confirmado por las consecuencias de ésta.

Richard Barnet destaca cómo, durante una reunión decisiva con un gru-

${ }^{17}$ Louis Halie, The Cold IVar as History, Londres, Chatto and Windus, 1967. Se trata de un libro magistralmente construido, que presenta la guerra fria desde el punto de vista convencional, como una lucha por mantener el equilibrio de poderes. 
Luciano Tomessini / La misión imposible del Presidente Nixon

po de lideres parlamentarios a principios de 1947, Dean Acheson (que acompañaba al Secretario de Estado Marshall) declaró que los Estados Unidos y la Unión Soviética "se encontraban divididos por un abismo ideológico insalvable". Para uno, "la democracia y la libertad individual eran básicas"; para la otra, "la dictadura y la conformidad absoluta". Adoptar las medidas necesarias "para apoyar a los paises amenazados por la agresión soviética o la subversión comunista equivalia a proteger la seguridad de los Estados Unidos' ${ }^{\prime 18}$. De esta manera se introdujo una confusión de alcances incalculables en la formulación de la doctrina Truman. El Nerw York Times pudo sacar las consecuencias que encerraba esta doctrina al dia siguientc de su anuncio: "Una época de aislamiento $y$ de intervenciones ocasionales ha terminado, y está siendo rcemplazada por una era de responsabilidad norteamericana".

El potencial intervencionista que contenia esta doctrina no ha cesado de hacerse patente. Al considerar los aspectos más ortodoxos de la politica internacional, se observa en el cambiante papel de las alianzas defensivas. En un comienzo los Estados Unidos concentraron todos sus csfucrzos en construir una sólida barrera para impedir que las tropas sovićticas, que ya se habian cstablecido en la mitad oriental de Europa, continuaran avanzando hacia occidente. Veinte años después de su establecimiento, la oTAN parece haber sido victima de su propio éxito. La amenaza que proporcionó una motivación común a todos sus micmbros ha desaparecido. En cambio, el predominio abrumador que ejercen los Estados Unidos sobrc sus aliados ha pasado a constituir el principal problema. De Gaulle fue un exponente de ese malestar. Aunque muchos se dcjaron impresionar más por su estilo que por la sustancia de su mensaje, el General no estaba expresando un trasnochado chauvinismo francés, sino que un problema europeo. Asi lo reconoció el ex comandante en jefe de la oran, General Lauris Norstad, en rg66: "Ustedes pueden eliminar a De Gaulle completamente del cuadro, $y$ no eliminarán el problema. Ustedes pueden eliminar a Francia del cuadro, pero no eliminarán el problema. El problema ha sido fundamental todo el tiempo. Siempre es conveniente tener una cabeza de turco. Eso nos proporciona una excusa para nuestras acciones o para nuestra falta de accionn'?

is Citado por Richard Barnes, op. cit., p. 115.

${ }^{19}$ General Lauris Norstad, Declaraciones al Subcomite de Seguridad Vacional y' Operaciones Internacionales del Seriado de los Estados Unidos, 6 de mayo, : 966 . 
ESTUDIOS INTERNACIONALES

El pretexto ha desaparecido, pero nada parece indicar que el problema haya sido eliminado. La unificación de Europa occidental era uno de los supuestos de la Alianzá Atlántica, pero Europa no se ha unido. Si algún dia lo hace, lo más probable es que este proceso tenga lugar en contra de los Estados Unidos.

La integración curopea no ha avanzado más precisamente porque esa ruptura todavia no se ha producido. Por esa misma razón, a fortiori, todavia cstá lejano el dia en que resurja una sola Europa de la amalgama de las dos mitades en que hoy se encuentra dividida. Existe un estrecho entrelazamiento cntre los problemas de la integración $y$ de la reunificación.europea; cl nexo es la contribución negativa de los Estados Unidos.

Más lamentable ha sido la suerte de los demás pactos militares. Con el correr de los años, la Unión Soviética perdió un tanto su fisonomia de "encarnación de las fuerzas del mal" para los Estados Unidos, tan sólo para ser reemplazada por China Comunista. Con implacable lógica de abogado, John Foster Dulles se puso a la tarea de reproducir en el mundo asiático la fórmula que en Europa habia cumplido sus objetivos inmediatos. Asi nació una maraña de tratados y' compromisos juridicos, particularmente los de SEATO. La homogeneidad cultural y politica que requieren estos pactos para ser operativos (que existia en alguna medida entre los miembros de la Alianza Atlántica) faltaba completamente en el caso de los paises asiáticos. Sólo algunos suscribicron esos tratados, y de ellos muy pocos eran estratégicamente importantes. El carácter intervencionista de la presencia norteamericana en Asia era demasiado evidente y' deterioraba la clicacia de esas alianzas.

Las alianzas militares han dejado de cumplir sus principales funciones. La necesidad de evitar un confrontamiento nuclear ha erosionado la credibilidad de los compromisos asumidos por los norteamericanos en defensa de sus aliados. Esto hace que sea tan dificil la liquidación de la guerra en Vietnam, y por eso durante su último viaje el Presidente Nixon tuvo que declarar en Bangkok (contradiciendo la doctrina que habia ido a promulgar): "Los Estados Unidos se lẹantarán orgullosamente junto a Tailandia contra todos los que puedan amenazarla desde adentro o descic afuera". (The Times, agosto, $19^{69}$ ). Por otra parte, la asistencia militar norteamericana ha servido a menudo para fines inesperados. Pakistán e Israel se valieron de clla para luchar contra la India y los paises árabes, respectivamente, $y$ no contra los comunistas como espe- 
Luciano Tomassini / La misión imposible del Presidente Nixon

raban los norteamericanos. Si a éstos las alianzas les sirven de algo todavia, es para mantener en línea a sus propios aliados.

\section{VIII}

Pero la politica globalista de los Estados Unidos rebasa, por definición, el marco más o menos bien delimitado de las clásicas esferas de influencia y de las alianzas militares. "Ningún agresor potencial puede suponer que la ausencia de un tratado defensivo, una declaración del Congreso, o de fuerzas de los Estados Unidos garantizan la impunidad de la agresión", dijo Dean Rusk en declaraciones reproducidas en The Washington Post (26 de agosto, 1966). Ese mismo año el Presidente Johnson, dirigiéndose a las tropas en Vietnam, afirmó: "Todo lo que ocurre en el mundo nos afecta, porque tarde o temprano llega a nuestra puerta" (The Vew York Times, 2 de noviembre). Tanto por su contenido como por su posterior desarrolio, la doctrina Truman se convirtió en una política destinada a defender el statu quo frente a cualquier cambio violento. Anticipándose a ella, el Secretario de Estado Byrnes habia declarado en 1946 que, aunque el orden de cosas vigente no era sagrado ni intangible, los Estados Unidos no permitirian que fuera objeto de ningún cambio unilateral20, y el Presidente Truman declaró un año más tarde: "No podemos permitir cambios en el statu quo por métodos tales como la coerción o mediante subterfugios tales como la infiltración politica"21. Naturalmente los Estados Unidos no se oponen al cambio, en general, ni al progreso. Por el contrario, ellos son los grandes defensores de la modernización y del desarrolio económico por la via de la "revolución pacífica". Sólo se oponen al cambio violento. Pero en un tiempo en que la historia se desarrolla bajo el signo de la liberación de los pueblos coloniales, en lo internacional, $y$ de la revolución de las expectativas en lo interno, es necesario prepararse para presenciar un poco de violencia: Muchas veces esta violencia se origina en las propias condiciones en que se desenvuelve el proceso de cambio; no siempre es inyectada artificialmente desde afuera.

"No nos oponemos - escribe Heilbroner ampliando esta idea- a lo que nosatros concebimos que debe ser el desarrollo cconómico. El proceso descrito como una "revolución

20 Citado en Richard Barnet, op. cit., p. 105.

${ }^{21}$ Ibid., p. 8. 
ESTUDIOS INTER NACIONALES

de las expectativas crecientes" es altamente atractivo. Conjura la imagen de un campesino en algún país primitivo, apoyado sobre su arado y mirando hacia el horizonte, en donde divisa oscuramente, pero por primera vez ( $y$ eso es lo que hay de revolucionario en esto), la visión de una vida mejor. De esa visión electrificante se desprende la necesaria catálisis que transforma la vieja y estagnada forma de vida. El ritrno de! trabajo se acelera. Las innovaciones, anteriormente temidas y resistidas, son aceptadas en forma ansiosa... Hay mucho de admirable en csta visión popular bien intencionada de la "revolución de las expectativas crecientes". Desgraciadamente, es más lo que ella encierra de engañoso. Porque el atractivo de esa retórica esconde o pasa por alto la mayor parte del espectro de las realidades que componen el proceso de desarrollo"22.

El desarrollo no puede efectuarse sin cambiar las instituciones, la estructura de las clases sociales, las ideas comúnmente admitidas. No es raro que encuentre resistencia. Es deseable, y a veces posible, que se verifique $\sin$ violencia. Pero eso no siempre ocurre. Al garantizar la conservación del statu quo contra toda tentativa de cambio violento en una época esencialmente revolucionaria, los Estados Unidos se comprometieron en una tarea que prácticamente equivalia a detener el reloj de la historia. Las implicancias de este compromiso fueron ágravadas debido a dos factores: el gradual obscurecimiento de la tradicional distinción entre guerras civiles y guerras internacionales, y la tendencia de las administraciones norteamericanas a medir todos los casos de insurgencia con la misma vara.

Gran parte de la violencia registrada en el mundo durante los últimos años ha tenido por causa movimientos revolucionarios producidos dentro de una misma nación y no conflictos entre Estados. Por lo demás, la creciente interconexión de los asuntos mundiales hace que tienda a borrarse la distinción entre "guerras" en el sentido tradicional de la palabra y las llamadas "guerras de liberación". A medida que se torna más problemático movilizar el poderio militar de los paises nucleares y aumenta la efectividad de la propaganda $y$ las comunicaciones, se incrementa el empleo de formas de influencia indirectas. "Los usos tradicionales del poder se han vuelto menos factibles, $y$ nuevas formas de presión han emergido como resultado de lealtades transnacionales y de estructuras domésticas débiles... Un radiotransmisor puede ser

${ }^{22}$ Robert L. Heilbroner, "Counterrevolutionary America", en Commentary, abril de 1607, p. 31. 
más efectivo que un escuadrón de B-52" ${ }^{23}$. De acuerdo con el derecho internacional, las autoridades legitimas de un Estado sólo tienen derecho a ser socorridas desde el exterior para sofocar una "rebelión", pero pierden ese derccho cuando los insurgentes son lo suficientemente fuertes como para sostener una verdadera "guerra civil", a menos que se demuestre que se encuentran bajo el control de una potencia extranjera. De ahi que los norteamericanos, para poder intervenir en los asuntos de otro pais, tengan que presumir la imbricación de los movimientos insurgentes locales con una acción subversiva exterior. En 1954, en medio de la crisis de Indochina, John Foster Dulles observó: "No es dificil movilizar la opinión pública mundial en contra de una agresión... pero otra cosa muy distinta es luchar contra cambios que se están produciendo en un pais por obra de agentes internos. Si queremos tomar posición en contra de una facción comunista en un pais extranjero, tendremos que actuar solos" 24 .

Los norteamericanos creen que existe un solo modelo de desarrollo (cuyos rasgos, por lo demás, corrcsponden a los de su propia socicdad inciustrial de consumo), un solo camino para lograrlo y una limpia oportunidad de llegar al punto de lake off para todos. Del mismo modo, creen que lodos los que "boicoteen" esta fórmula son comunistas y tienen grandes dificultades para diferenciar a unos de otros. Refiriéndose al caso de Grecia (con el cual se inauguró la guerra fría), Richard Barnet observa que cr aquella época la crisis pudo haber sido definida como una manifestaciỏn más de los crónicos enredos balcánicos, como resultado de las agudas tensiones sociales existentes o como una natural reacción politica contra la oligarquia en el poder. En cambio, para deliniria se la proyectó contra el telón de fondo de un connicto global de naturaleza idcológica. Posteriormente, los nortcamericanos han aplicado el mismo procedimiento para definir cualquier estallido de violencia. Debajo del barniz de sus idcologias (si es que profesan alguna), la majoría de los revolucionarios posee fuertes motivaciones locales por la sencilla razón de que para romper con el sistema en que viven necesitan ser movidos por una fuerte carga emocional y ésta, por lo general, proviene de fuentes muy cercanas. Por lo demás, por definición el revolucionario

${ }^{23}$ Henry A. Kissinger, op. cil., pp. 56 y fo.

${ }^{24}$ Citado por Richard Barnet, op. cit., p. 258. 
E S T U D IOS $1 \therefore$ T E R $\therefore$ A C I O $\therefore$ A L E S

está más intercsado en destruir el sistema imperante que en construir uno nuevo. Como al fin y al cabo tienc que proponer alguna alternativa, lo hace adoptando como modelo la experiencia de la última revolución. triunfante. Los bolcheviques rusos trataron de repetir en Petrogrado los succsos de la Comuna de Paris; los comunistas chinos pretendieron reproducir la revolución de octubre en Cantón, y los vietnamitas intentaron reeditar en su pais la revuelta campesina china. A la larga, todos los revolucionarios terminan adaptando su modelo a las condiciones locales, o dejándoio lisa y llanamente de lado. Por lo general, el proceso de adaptación del modelo, o de ruptura con él, se acentúa a medida que los nuevos grupos revolucionarios dejan de depender del apoyo de sus camaradas del exterior, necesario durante las primeras etapas de su lucha armada. Los norteamericanos han desestimado invariablemente el ingrediente local de las revoluciones. La "teoria del domino" ha hecho el resto. Juzgando que todos los casos de insurgencia son subsidiarios de una ideologia común, a la cual previamente han declarado la guerra, los Estados Unidos se han impuesto un formidable desafio. .

"El ahora obsoleto punto de vista de que la gucrra fria fue básicamentc un conflicto en tomo a un conjunto de problemas $y$ de áreas más o menos claramente definido fuc planteado primero con urgencia en 1947 , en ln época en que la doctrina Truman fue proclamada. Dicha doctrina trató de presentar el conflicto cntre la Unión Soviética y los Estados Unidos como una lucha cntre "dos formas de vida", y por consiguiente -como se argumentó entonces- cré la amenaza de extender las cuestiones en litigio hasta un dominio metafisico en el cual no scria posible alcanzar ninguna solución que no fuera la victoria total de una de las dos partes"25.

La guerra fria nunca tuvo las caracteristicas de un simple conflicto de poderes, pese a lo que piense Louis Halle. Fue más bien, como expresa David Horowitz, una contienda apocaliptica entre dos formas de vida. Sólo falta agregar que, al extenderse al mundo entero, esa contienda se transformó en la lucha de un sistema (el sistema caracteristico de las sociedades industriales) por extenderse o, al menos, por eliminar todo elemento que pudiera constituir una amenaza u oponerle una barrera.

$I X$

Los detractores liberales (pero, como hemos visto, indulgentes) del globalismo norteamericano han sido los primeras en denunciar la confusión

25 David Horowitz (ed), Contaimment and Revolution, Londres, Anthony Blond, 1967, p. 10. 
de lo que pudo ser un conflicto de poderes con una confrontación en torno a valores absolutos. Los Estados Unidos definieron en términos ideológicos, y potencialmente universales, un litigio que debió haber quedado confinado dentro de limites geográficos bien precisos. A juicio de tales críticos, al hacerlo cometió un error. Como consecuencia de esa equivocación, los Estados Unidos comenzaron a asumir responsabilidades que no estaban en condiciones de cumplir. "Una politica exterior basada en una hostilidad activa contra un movimiento político mundial, tal como el jacobinismo, el liberalismo o el comunismo, confunde la csfera del juicio filosófico o moral con el dominio de la acción politica, y por esta razón tiene que fracasar. Porque hay límites más bien estrechos, definidos por los intereses que están en juego y el poder de que se dispone, dentro de los cuales una politica exterior tiene alguna posibilidad de triunfar, y una politica exterior que se oponga a la revolución comunista a través de todo el mundo sobrepasa esos limites" 26 . La recomendación de estos críticos es la de que los Estados Unidos se retire de las posiciones a que ha llegado a consecuencia de esta "cruzada" y vuelva a fundar su politica exterior en los requerimientos especificos de sus "intereses nacionales".

Se proponen tres maneras de conseguir este objetivo. La primera consiste en redefinir las relaciones con los demás miembros del club de los paises industrializados, asignándoles una muy alta prioridad pero pidiéndoles, a! mismo tiempo, que asuman su cuota de responsabilidad en los asuntos mundiales junto con los Estados Unidos. Lamentablemente para los defensores de esta fórmula, ni los paises de Europa occidental ni Japón parecen muy dispuestos a aceptar las consecuencias de ella. La segunda aboga por una vuelta al concepto de las esferas de interés o de las esferas de influencia. Pero en nuestro tiempo los conceptos de "interés" e "influencia" se han vuelto extremadamente difusos. En la práctica, denotan realidades que aparecen bajo formas cada vez más indirectas o que sólo pueden ser reconocidas a posteriori. Por eso algunos proponen una tercera solución, más sofisticada que las anteriores, basada en una aplicación más fina, más restringida y más discriminada del concepto del "interés nacional", con lo cual volvemos al punto de partida. Porque ¿cuándo está y cuándo no está en juiego el interés nacional de los Estados 
Unidos? La tesis de este articulo es que los estadistas norteamericanos, desde Truman hasta Johnson, supieron reconocerlo mejor que los críticos liberales de la política exterior que ellos diseñaron. Al fin y al cabo, la Casa Blanca está más cerca del Capitolio, y ambos más cerca de los intereses norteamericanos, que los académicos en sus universidades. Si esos intereses se identifican con la supervivencia y la expansión del sistema industrial norteamericano, asi como de la forma de vida y del sistema de valores en que éste se fundamenta, entonces una definición ideológica los interpretaba mejor que una definición geográfica.

El Presidente Nixon ha recibido el mandato de poner término a una era de globalismo en la politica exterior norteamericana. Se ha hecho notar más arriba que las posibilidades de que Nixon cumpla con este mandato se reducirán en la medida én que esa politica esté fundada en la naturaleza $y$, en un sentido muy amplio, en las necesidades del sistema económico y social de su país. Lo sorprendente es que todavía no se haya hecho un esfuerzo serio para contestar a esa pregunta.

Los cientistas politicos como Kissinger, que vaticinan la emergencia de un mundo "militarmente bipolar pero políticamente multipolar", razonan como si las relaciones internacionales no tuvieran nada que ver con las realidades económicas. A ellos les basta comprobar las crecientes dificultades que existen para traducir el poderio militar en influencia política para saltar a la conclusión de que esto significa el fin de la hegemonia de las grandes potencias. Incluso uno se siente tentado de pensar que si llegan con tanta facilidad a esta conclusión es porque realmente no creen en ella. Seria humano y disculpable que sintieran algo de pesar al enfrentarse con esta capitis diminutio. Pero hay una falacia en su razonamiento. Partiendo de la premisa de que los recursos militares de las grandes potencias ya no se traducen automáticamente en influcncia política, la única conclusión a que puede llegarse es que el esfuerzo militar actualmente no produce los resultados que serian de esperar y que, por consiguiente, debe ser reducido. Es erróneo concluir que por ello las grandes potencias perderán su primacia: ésta puede ser asegurada por otros medios. Stanley Hoflmann ha observado que la posesión de determinadas ventajas está dejando de scr el principal objetivo de la politica internacional de las grandes potencias, y está siendo reemplazado por el interés en influenciar o modelar de acuerdo con sus valores propios el ambiente 

internacional27. Es dificil que el aparato militar de los Estados Unidos sirva para lograr esos fines; lo más probable es que constituya un obstáculo. Las grandes potencias tienen otros medios para conservar su primacia, aparte de los militares. La politica internacional no puede ser separada de sus fundamentos económicos.

Si uno vuelve su mirada hacia el campo de la economia, se encuentra con el mismo silencio. John Kenneth Galbraith, en un libro histórico*, hizo un análisis penetrante del "nuevo estado industrial", cuyo clemento central es la gran corporación (o, como él la llama, la "tecnoestructura"), especialmente diseñada para controlar el mercado. Resultaba inevitable deducir las consecuencias de ese análisis en el plano mundial y cstudiar, a partir de esos supuestos, el comportamiento internacional de las grandes corporaciones. Pero Galbraith no lo hizo. Si nos contentáramos con su lectura, nos quedariamos sin saber que las grandes firmas norteamericanas tienen intereses en e! exterior.

$x$

La tesis comúnmente aceptada sostiene que el sector externo es una parte insignificante de ia cconomia norteamericana. En efecto, si se compara el aporte del comercio extcrior nortcamericano con cl producto nacional bruto del mismo pais, se verá que el primero constituye una proporción muy pequeña que, además, tiende a decrecer. Basándose en esta observación, muchos están persuadidos de que el "imperialismo" norteamericano está reñido con la realidad económica. Los Estados Unidos podrán ser un pais politicamente intervencionista, pero es aislacionista en lo económico. Este planteamiento olvida el cambio más importante ocurrido en la economia internacional durante los últimos años. Los paises industriales, y especialmente los Estados Unidos, ya no están tan interesados en vender sus productos en el extranjero como en producirlos alli. El énfasis se ha desplazado desde el comercio internacional a la producción internacional. Los

27 Ver Staniey lloTman, Gulliver's Troubles, or The Selling of American Forcign Policy, New York, McGraw Hill, :968, especiaimente pp. 57 y siguientes.

"N. de la R. El libro aludido es "The Nerv Industrial State", s967. 
E S T U D I OS I N TER N A C I O N $A$ L E

supuestos sobre los cuales ha operado la economia moderna desde que los acuñaran Adam Smith y sus sucesores, ya no corresponden a la realidad. De acuerdo con esos conceptos, los bienes sc desplazaban internacionalmente, pero los factores de la producción no. Por eso habia que fomentar la libertad de comercio, y establecer una sana división internacional del trabajo. El comercio internacional tenia gran importancia pero, fuera de esos intercambios, cada economia funcionaba firmemente enmarcada dentro de las fronteras nacionales. Todo cso ha sido alterado por la internalización de.la producción. "La era de la producción internacional ya se ha iniciado, $y$ su instrumento es la corporación internacional's28.

El nuevó sistema industrial se basa en el uso intensivo de la tecnologia avanzada. Galbraith asocia a ese rasgo una serie de otras caracteristicas. Primero, entre la decisión de producir y la llegada del producto al mercado transcurre un lapso de ticmpo cada vez más largo, que puede ser de varios años en el caso de rubros medianamente complejos como automóviles o aviones. Segundo, también es necesario comprometer un mayor volumen de capital y ascgurair con la debida anticipación la disponibilidad de personal especializado. Tercero, como consecucncia de lo anterior, la capacidad del aparato industrial para cumplir determinadas tareas se lorna más inflexible, no pudiendo ser reorientada con relativa facilidad hacia el cumplimiento de otras. De todo ello se desprende la imperiosa necesidad de controlar el mercado. El nuevo sistema industrial no puede funcionar de acuerdo con "las leyes de la oferta y la demanda". Para poder planificar la oferta, la demanda tiène que ser modelada. La respuesta a esta necesidad es la corporación gigantc, que opera en estrecha coordinación con cl Estado.

Si alguien retomara este análisis donde Calbraith lo dejó, llegaria a la conclusión de que la necesidad de controlar el mercado (o por lo menos de situarse por encima de sus alternativas) diversificando sus actividades, detcrmina que la "tecnoestructura" adquiera una dimensión internacional. Y precisamente eso es lo que está ocurriendo. La

28 Sidney Rolle, "Updating Adam Snith", en Interplay, noviembre de 1968, p. 15. Ver tambien Edith r. Penrose, The Large International Firm in Developing Countries, Londrs, Allen \& Unwin, 1968, con especial referencia al Medio Orientc, y Celso Furtado, La Concentración del Poder Económico an los Estados Unidos y sus Projecciones an dimirica Latina, en Estudios Internacionates, Año I, $N^{\circ} 3-4$. Stgo. de Chilc. 
totalidad de las inversiones directas efectuadas en el extranjero por los paises exporladores de capital (incluyendo naturaimente las inversiones realizadas por cualquicra de csos paises en otros del nismo grupo) alcanzan un volumen de aproximadamente go billones de dólares*. Poco menos los dos tercios de este monto corresponde a inversiones nortcamericanas. La expansión de las inversiones nortcamericanas en el cxicrior ha sido muy acentunda: de un tota! de 7 billones de clólares al finalizar la Scgunda Gucra Mundial se pasó a 25 billones en 1957 , y a 55 en $1966^{29}$. Estos antecedentes alteran por completo la tesis oficial relativa a la insignificancia del sector cxterno dentro de ia economia norteamericana. Ahora es posible comprobar que csa apreciación descansaba sobre ciertos subterfugios. Por una parle, lo que se consideraba era el Blyjo anual, tanto comercial como de capitales, y no las inversiones en el exterior. Por otra, sc comparaban esas mangnitudes con cl producto nacional bruto de los Estados Unidos, concepto en el cual se incluyen rubros tales como los gastus públicos, actividades financicras $y$ servicios personales. Las inversiones en el exterior tienen un carácter cumulativo y representan un producto anun! equivalente al doble de su volumen. Un cáleulo hecho sobre la base de informaciones correspondientes a 1964 llega a la conclusión de que el producto proveniente de inversiones en el exterior, tanto directas como de otra naluraleza, fue de 433 billones de dólares, lo que sumado a las ventas en el extranjero por concepto de cxportaciones da un total de 168 billones de dólares. El valor total de los bienes producidos en los Estados Unidos en $196_{4}$ (exceptuanclo los inmuebles) es cstimado en 280 billones de dólares. Por consiguiente, el tamaño del mercado externo (para las exportaciones $y$ los productos provenientes de inversiones en el cxterior) resulta ser considerable para la cconoma norteamericanat ${ }^{30}$.

Las proyecciones internacionales de la economia norteamericana no sc reflejan sólo en esas magnitudes. Son la consecuencia de un sistema industrial que, en la medida en que está basado en la innovación tecnológica $y$ supone el control de mercarlos cada ve\% más amplios, es

- Ni. Ac la R.: 1 billón - mil millones en Estados Unitlos.

29 Cifras glnbales tomadas de Sidney' Rolfe, $0 p$. cit.

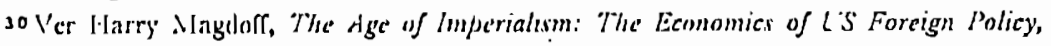
New Vork, Nonthly Review Press, 19 (igg, especialmente pp. 177 y' siguientes. 
ESTUDIOS INTERNAGIONALES

intrinsecamente expansivo, como lo es la forma de vida que constituye a la vez su fundamento y resultado. Lo esencial para la sociedad norteamericana no es tanto la obtención de beneficios actuales mediante actividades en el exterior, sino que otras sociedades estén potencialmente abiertas a su penetración, para lo cual deben compartir sus valores y' adoptar los rasgos fundamentales de su sistema de vida. "Nosotros no insistimos, dijo el Presidente Nixon en el Mensaje sobre Ayuda Externa que envió este año al Congreso (The New York Times, 29 de mayo, 1969), en que los paises en desarrollo imiten el sistema norteamericano. Cada nación debe modelar sus propias instituciones de acuerdo con sus necesidades. Pero el progreso ha sido mayor alli donde los gobiernos han alentado la empresa privada, soltado los controles burocráticos, estimulado la competcncia y abierto el máximo de oportunidades para la iniciativa individual". Los intereses vitales de los Estados Unidos coinciden con los de un sistema industrial y una sociedad de consumo intrinsecamente expansivos. İn la era postmundial -la hazaña del Apolo xi subraya simbólicamente la crecicnte interdependencia de los tripulantes de la tierra- Norteamérica tiene que empeñarse en que en la mayor parte del mundo prevalezcan valores compalibies con ese sistema de vida. No puede mirar con buenos ojos que algunas regiones permanczcan marginalas, $y$ no puede tolerar el sorprendente efecto de demostración que podria derivarse de la creación de un sistema en que los valores tecnológicos no tengan la primacia y que no esté motivado por el espejismo del consumo. Esto encicrra una tarea que trasciende los parámetros de un conflicto particular de podercs. Implica un compromiso idcológico.

"La cultura industria! avanzadia es, en un scrtidlo específico, más idcológica que su predccesora, en tanto que la ideología se encuentra hoy' en el propio proceso de producción. Bajo una forma provocaliva, esta propessición revela los aspectos políticos de la racionalidad tecnológica predominante. El aparato productiva, y les bienes y' scrvicios que produce, "venden" o imponen el sistena socia! como un todo. Los medios de transporte y comunicación de masas, los bienes de vivienda, alimentación y vesuario, el irresistible rendimiento de la industria de las diversiones $y$ de la información, llcvan consigo hábitos y actitules prescritas. Los productos adoctrinan $y$ manipulan; promueven una conciencia inmune a su falsedad. I' a metida que esos productos son asequibles al más individuns en más clases sociales, el adoctrinamiento que llevan a cabo deja de ser publicidad; se convierte en una forma de vida. 
Luciano Tomassini / La misión imposible del Presidente Nixon

Es un buen modo de vida - mucho mejor que el de antes - y en cuanto tal se opone al cambio cualitativo" 31 .

Ese es el verdadero fundamento del globalismo norteamericano. La historia y el estado anímico de su pais han hecho responsable al Presidente Nixon de poner en práctica la estrategia de la retirada. Quizás se le haya encomendado una misión imposible.

Septiembre, 1969.

31 Herbert Marcuse, One-Dimensional Man (tomado de la traducción española, Barcelona, Editorial Seix Barral, 1968, pp. $4^{t}$ y $4^{2}$ ). 